\title{
BMJ Open Knowledge, attitude and experience of episiotomy practice among obstetricians and midwives: a cross-sectional study from China
}

\author{
Jingxuan Yang, Hua Bai
}

To cite: Yang J, Bai H. Knowledge, attitude and experience of episiotomy practice among obstetricians and midwives: a cross-sectional study from China. BMJ Open 2021;11:e043596. doi:10.1136/ bmjopen-2020-043596

- Prepublication history for this paper is available online. To view these files, please visit the journal online (http://dx.doi. org/10.1136/bmjopen-2020043596).

Received 11 August 2020 Revised 03 March 2021 Accepted 01 April 2021

\section{Check for updates}

(c) Author(s) (or their employer(s)) 2021. Re-use permitted under CC BY-NC. No commercial re-use. See rights and permissions. Published by BMJ.

The Third Affiliated Hospital, Zhengzhou University, Zhengzhou, Henan, China

Correspondence to Professor Hua Bai; sfyhlb3726@zzu.edu.cn

\section{ABSTRACT}

Objective Episiotomy is still performed widely by obstetricians and midwives in some Chinese maternity units, but the reasons are unknown. This study aims to determine the knowledge, attitude and experience towards the practice of episiotomy among obstetricians and midwives in China's public hospitals and consider strategies to reduce its practice.

Methods A cross-sectional web survey using a selfadministered questionnaire was conducted among obstetricians and midwives in 90 public hospitals in Henan Province, China.

Results 900 (82.21\%) participants completed the questionnaire. Average knowledge level $(4.15, S D=1.10)$ on complications and overuse was identified among participants. Episiotomy was performed more frequently in secondary hospitals than in tertiary hospitals $(p<0.05)$. Senior clinicians were more likely to perform episiotomy than younger ones $(p<0.05)$. Almost half of the clinicians $(42.11 \%)$ considered the current rate of episiotomy (45\%) to be right or too low. The most common reason for performing episiotomy identified by obstetricians (83.94\%) and midwives $(79.69 \%)$ was to reduce third-degree or fourth-degree perineal laceration. Both obstetricians $(80.29 \%)$ and midwives (82.57\%) agreed that the most significant obstacle to reducing the rate of episiotomy was lack of training on reducing perineal tears.

Conclusion In sum, episiotomy was driven by previous training, practitioners' experience and local norms rather than the latest medical evidence. Clinicians in secondary hospitals and senior clinicians are key training targets. It is urgent to improve current clinical policies and surgical procedure guidelines for obstetricians and midwives regarding episiotomy.

\section{INTRODUCTION}

Episiotomy is the surgical incision that cuts the vaginal mucosa, superficial perineal muscles and a few fibres of the levator ani (the muscle of the pelvic floor and the anterior fascicles hold both sides of the urethra and the vagina). Episiotomy originated in the 18th century as a preventive measure. ${ }^{1}$ Its purpose is to enlarge the vaginal outlet and facilitate labour. Episiotomy needs to be performed
Strengths and limitations of this study

- No study has yet investigated the knowledge, attitude and experience towards episiotomy among Chinese to date.

- The impact of hospital level, work experience and their interactions were explored.

- The role of the nursing association facilitated the generalisability of the results.

- Self-reported measures enhanced disclosure of information about sensitive topics such as personal episiotomy rate.

- The cross-sectional nature of the data limits the ability to infer a causal relationship between attitude and practice.

when there is poor perineal tissue elasticity that perineal tear is deemed inevitable, for maternal or neonatal pathological conditions that require ending the delivery urgently, for operative vaginal births, and when preterm fetal head is obviously compressed; and needs not for stillbirth, no vaginal delivery. Traditional views are that routine episiotomy can reduce the pressure of the fetal head on the pelvic floor tissues and prevent third-degree or fourth-degree perineal laceration and that it is easy to suture because open wound is smoother than spontaneous wound. ${ }^{2}$ Moreover, based on the traditional view that Asian women have shorter perineal length than Caucasians, putting them at increased risk of tears, ${ }^{3}$ episiotomy is still routinely performed in some hospitals in China. Episiotomy is essentially a type of birth injury and does not reduce the incidence of severe perineal lacerations, and instead increases the risk of complications including perineal lacerations, perineal pain (compared with no laceration), puerperal infection, postpartum haemorrhage and later dyspareunia. ${ }^{4}$ Thus, many obstetricians have begun to limit the use of episiotomy in recent years. 
Internationally, the American College of Obstetricians and Gynecologists recommended against routine episiotomy in 2006. The National Quality Forum regarded the use of restrictive episiotomy as an important way to ensure safety of patients in $2008 .^{5}$ The rate of episiotomy recommended by the WHO is under $10 \%$, and is only used during complicated vaginal deliveries (breech, shoulder dystocia, forceps or vacuum extraction), scarring from female genital mutilation or poorly healed obstetrical anal sphincter injuries, and fetal distress. ${ }^{6}$ The Royal College of Obstetricians and Gynaecologists recommended operative vaginal birth as the only indication. ${ }^{7}$ The French National College of Gynecologists and Obstetricians (CNGOF) did not recommend routine episiotomy in specific obstetric situations. ${ }^{8}$ The clinical guidelines for operative vaginal delivery (2016) by the Obstetrics Group, Obstetrics and Gynecology Society, Chinese Medical Association recommended restrictive episiotomy in 2016. ${ }^{9}$ Another study also suggested that episiotomy is used only if there was an indistinct indication of imminent tearing. ${ }^{7}$

There is wide variation in the rates of episiotomy all over the world, from developed countries such as Denmark $(4 \%),{ }^{10}$ Sweden $(9.7 \%)$, the UK $(12 \%-15 \%)$ and the USA $(11.6 \%)^{1112}$ to developing countries including Saudi Arabia (45\%), ${ }^{13}$ India (60\%), ${ }^{14}$ Jordan (67\%), Yemen $(75.1 \%),{ }^{15}$ Cambodia $(94.5 \%)^{16}$ and China Taiwan $(100 \%),{ }^{12}$ which are still very high compared with the $10 \%$ recommended by the WHO. ${ }^{6}$ However, in 2010, the prevalence of third-degree or fourth-degree tears was not significantly different in Denmark $(4.1 \%)$, Sweden $(3.5 \%)$, the UK $(2.4 \%-3.2 \%)$, the USA $(4.9 \%)$, India $(2.1 \%)$ and China $(4.9 \%) \cdot{ }^{17-19}$ The infant outcomes are similar for selective episiotomy and routine episiotomy as well. ${ }^{20}$ In China, episiotomy used to be a routine practice for vaginal delivery. In the last decade, hospital data reported rates of $47.4 \%-84.7 \%,{ }^{21-23}$ and some multicentre studies reported hospital rates of $41.2 \%-69.7 \% .^{24}{ }^{25}$ In China, there were 17.23 million births in $2016^{26}$ and as many as 7.33 million women underwent an episiotomy a year (given a vaginal birth rate of $61 \%$ and an episiotomy rate of $69.7 \%$ among vaginal births). ${ }^{24}$ Although the Chinese national obstetric guideline by the Obstetrics Group, Obstetrics and Gynecology Society, Chinese Medical Association has recommended restrictive use of episiotomy since 2016, it has not been fully implemented. ${ }^{9}$ The main reasons for the high rates of episiotomy are lack of training, local national norms and fear of severe perineal injury in poor and middle-income countries. ${ }^{27}$

Zhang et $a t^{28}$ explored the risk factors for episiotomy during vaginal delivery in Western China. The results revealed that the overall rate of episiotomy was $44 \%$, including among nulliparas (52.9\%) and multiparas $(18.4 \%)$. The study identified the risk factors for episiotomy were being nulliparous, prolonged second stage of labour and shortage of human resource in the delivery room. The risk factors among nulliparas included advanced maternal age, increased biparietal diameter, more than 10 hours in the first stage of labour and increased neonatal weight. Senior midwives and obstetricians were more likely to perform episiotomies due to difficulties adjusting their clinical practice according to the latest evidence-based medicine. The study recommended that researchers further examined the barriers to change through a survey of knowledge and attitude of midwives.

As a decision-maker for episiotomy, midwives often rely on their own experience to judge and have not yet formed a unified decision standard. The reasons for the ongoing wide use of episiotomy are also unknown. ${ }^{29}$ Reliable and current information on the attitudes of obstetricians and midwives towards episiotomy is needed. Chinese studies mainly focus on the practice of episiotomy and ignore this important topic. Therefore, this paper aims to determine the knowledge, attitude and experience of the practice of episiotomy of midwives and obstetricians in public hospitals in China. The feedback results in turn would also accelerate standardised training to improve the practice of episiotomy.

\section{MATERIALS AND METHODS Design}

The study was a web-based cross-sectional survey. The questionnaires were distributed online in December 2019 and the results were collected within 2 months in succession. We used convenience sampling in 90 hospitals joining the forum of the Obstetrics and Gynecology Branch of the Nursing Association, consisting of 32 tertiary hospitals, 47 secondary hospitals and 11 primary hospitals. These hospitals care for an average of about 20000 women and newborns each year. Midwives are responsible for managing pregnant women without complications and with normal vaginal delivery. Obstetricians manage all high-risk, operative and nulliparous deliveries. In 2019, the rate of episiotomy among vaginal deliveries was diverse at these hospitals, with an average of $45 \%$. There was an imbalance in that more than threequarters of women who had an episiotomy were primiparas and less than $10 \%$ were multiparas. The average rate of episiotomy was used as one item to assess participants' attitudes about episiotomy rate.

Hospitals in China are classified as primary, secondary and tertiary institutions according to the ability to provide medical care and medical education and to conduct medical research. Primary hospitals provide prevention, medical treatment, healthcare and rehabilitation services to communities of a given population directly. Their main functions are to provide primary prevention directly to the population, manage patients with frequent and common diseases in the community, make correct referrals for severe diseases, assist high-level hospitals in intermediate or posthospital services, and reasonably divert patients. Secondary hospitals are regional hospitals that provide comprehensive health services to multiple communities. Their main functions are to participate in the guidance of 
high-risk population monitoring, accept first-level referrals, provide technical guidance to first-level hospitals, and carry out teaching and scientific research to a certain extent. Tertiary hospitals provide high-level specialised medical services and carry out higher education, scientific research tasks in several regions. Their main functions are to provide specialised medical services, solve serious diseases, accept second-level referrals, provide technical guidance and train talents for lower-level hospitals, complete the training of various senior medical professionals, and undertake the task of provincial or above scientific research projects.

In China, most women give birth in common wards, and only some women have the opportunity to give birth in single wards. Hospitals $(76 \%)$ have the necessary conditions for epidural analgesia and a unified labour analgesia process, but only $20 \%$ of the units use labour analgesia as a routine method during vaginal births. ${ }^{30}$ About $30 \%$ of women would choose companion labour but need charge. Also only one family member is allowed.

\section{Participants}

All obstetricians $(\mathrm{n}=196)$ and midwives $(\mathrm{n}=899)$ who provided fetal delivery services in selected hospitals were eligible to participate in this survey. Inclusion criteria comprised all obstetricians and midwives who had the opportunity to perform episiotomies and provided care for women during delivery. Exclusion criteria included all obstetricians and midwives who provided care but had not had the opportunity to perform episiotomies, for example, nurses who worked in antenatal clinics and postnatal wards. Eligible participants were identified by departmental heads, those who participated in the forum and supported the study. Department heads distributed the self-administered online questionnaire on behalf of researchers through the WeChat group. They had no right to read the answer or determine who completed the questionnaire. The staff were free to complete the survey or not without giving any reason.

\section{Patient and public involvement}

The respondents of this paper are obstetricians and midwives. Patients and the public were not involved in this study.

\section{Data}

An anonymous, self-administered online questionnaire included an introduction and invitations to complete the questionnaire. It was designed to investigate the knowledge, attitude and experience of episiotomy of midwives and obstetricians in Chinese public hospitals. Participants were informed to complete and submit the questionnaire online. This questionnaire was developed from literature review and expert panel advice, ${ }^{2}{ }^{31-33}$ and the questions had been used in previous studies. ${ }^{27} 34$ The questionnaire was initially drafted in English and then underwent the 'forward-backward-forward' translation from English to Chinese and then to English again by another translator from the School of Languages, Zhengzhou University. A bilingual expert did the translation to maintain content meaning over a word-for-word literal translation. Back translation to the original language version (English) was done without access to the initial English version questionnaires. The questionnaire was then assessed for equivalency to the original and back-translated versions and was ascertained to be satisfactory by a panel of experts. No significant modifications were identified, showing that the scale maintained its meaning and purpose.

The questionnaire consisted of four parts. The first part was participants' characteristics, including vocation (midwife or obstetrician), gender, work experience and hospital level. The second part included questions on practice of episiotomy, frequency of use of episiotomy in nulliparous and multiparous women, type of episiotomy (midline, mediolateral) and reasons for use of episiotomy. The third part collected knowledge related to the outcomes of routine use of episiotomy. These questions had been used in previous studies, ${ }^{27}{ }^{34}$ including the risk of postpartum haemorrhage, neonatal distress, wound healing/complications, perineal pain, urinary incontinence and pelvic organ prolapse. The fourth part collected data about participants' attitudes towards episiotomy using questions derived from related sections in previous studies. ${ }^{27} 34$ These included views on the average rate of episiotomy of delivery units in Henan Province (too high, too low, about right), appropriateness of routine episiotomy policy for nulliparous and multiparous women, and perceived barriers to reducing rate of episiotomy.

Approved by the ethics committee, the questionnaire was piloted with five midwives and five obstetricians. There were no changes required based on the outcome of the pilot test. The questionnaire took $5-10 \mathrm{~min}$ to complete.

\section{Data analysis}

We used frequency tabulations, contingency tables, unpaired t-test, homogeneity of variance test and analysis of variance (ANOVA) to analyse data. Participants were divided into two categories (midwife or obstetrician) according to occupation. We first conducted a descriptive statistical analysis by calculating proportions, knowledge score and SD. To mitigate the effect of an unequal proportion of sample and distinguish the differences between midwives and obstetricians, we next carried out unpaired t-test and homogeneity of variance test. Finally, ANOVA was used to explore the effects of hospital level, work experience and the experience $\times$ hospital level interaction $(\mathrm{p}<0.05)$. Data were analysed by the Stata 14 software. ${ }^{35}$

Knowledge score ranged from 0 to 6 . Answers were assigned 1 point for correct answers and 0 for incorrect or unknown assignments. The correct answers included that episiotomy increases the risk of postpartum haemorrhage and wound complications (compared with women with second-degree laceration), but does not increase the risk of fetal distress, perineal pain (compared with women 


\begin{tabular}{|c|c|c|c|}
\hline & $\begin{array}{l}\text { Obstetricians } \\
\mathrm{n}=137\end{array}$ & $\begin{array}{l}\text { Midwives } \\
\mathrm{n}=763\end{array}$ & $\begin{array}{l}\text { Total } \\
\mathrm{N}=900\end{array}$ \\
\hline & n (\%) & n (\%) & n (\%) \\
\hline \multicolumn{4}{|l|}{ Gender } \\
\hline Male & $1(0.73)$ & $2(0.26)$ & $3(0.33)$ \\
\hline Female & $136(99.27)$ & 761 (99.74) & 897 (99.67) \\
\hline \multicolumn{4}{|c|}{ Experience (years) } \\
\hline$<5$ & 26 (18.99) & 150 (19.66) & 176 (19.56) \\
\hline $5-10$ & 26 (18.99) & 241 (31.59) & 267 (29.67) \\
\hline $11-20$ & $37(27.01)$ & $219(28.70)$ & $256(28.44)$ \\
\hline$>20$ & 48 (35.01) & $153(20.05)$ & 201 (22.33) \\
\hline \multicolumn{4}{|c|}{ Hospital level } \\
\hline Level 1 & $9(6.57)$ & $28(3.67)$ & $37(4.11)$ \\
\hline Level 2 & $60(43.80)$ & 343 (44.95) & 403 (44.78) \\
\hline Level 3 & 68 (49.64) & 392 (51.38) & $460(51.11)$ \\
\hline
\end{tabular}

with second-degree laceration), urinary incontinence and pelvic organ prolapse.

\section{RESULTS}

\section{Descriptive characteristics of participants}

We finally collected 900 valid questionnaires with an effective recovery rate of $82.21 \%$. A total of 900 valid questionnaires from 137 obstetricians and 763 from midwives were collected. Two researchers reviewed the validity of the questionnaires. The information from 99 questionnaires was incomplete, 77 questionnaires were submitted in less than $60 \mathrm{~s}$, and feedback from another 19 questionnaires was far from clinical facts, so we removed all of them from the valid questionnaires. Majority of the obstetricians and midwives were women, accounting for $99.27 \%$ and $99.74 \%$, respectively. There was no significant statistical difference $(\mathrm{t}=3.005, \mathrm{p}=0.104)$ between midwives and obstetricians in their work experience providing maternal care, with $176(19.56 \%)<5$ years, 267 (29.67\%) 5-10 years, 256 (28.84\%) 11-20 years, and 201 $(22.33 \%)>20$ years. There was also no significant difference in hospital level between midwives and obstetricians $(\mathrm{t}=0.868, \mathrm{p}=0.123)$, consisting of $37(4.11 \%)$ from primary hospitals, $403(44.78 \%)$ from secondary hospitals and 460 $(51.11 \%)$ from tertiary hospitals (table 1 ).

\section{Practice situation of episiotomy among participants}

Table 2 reports the practice of episiotomy of obstetricians and midwives. Almost all participants (97.67\%) performed mediolateral episiotomies, while $21(2.33 \%)$ performed midline episiotomies. There was no significant difference in the direction of episiotomy used between midwives and obstetricians $(\mathrm{p}=0.506)$. Of the midwives and obstetricians, $90.30 \%$ and $90.51 \%$, respectively, reported performing the mediolateral 4-5 o'clock approach, and $28.44 \%$ and $24.09 \%$ reported they used
Table 2 Use of episiotomy between obstetricians and midwives

\begin{tabular}{|c|c|c|c|}
\hline & $\begin{array}{l}\text { Obstetricians } \\
\mathrm{n}=137\end{array}$ & $\begin{array}{l}\text { Midwives } \\
\mathrm{n}=763\end{array}$ & \\
\hline Use of episiotomy & n (\%) & $\mathrm{n}(\%)$ & value \\
\hline Nulliparous & & & 0.238 \\
\hline $\begin{array}{l}\text { Almost } 90 \%-100 \% \text { of } \\
\text { the time }\end{array}$ & $3(2.19)$ & $68(8.91)$ & \\
\hline $60 \%-90 \%$ of the time & $30(21.90)$ & 149 (19.53) & \\
\hline $30 \%-60 \%$ of the time & $56(40.88)$ & $264(34.60)$ & \\
\hline$<30 \%$ of the time & $48(35.04)$ & $282(36.96)$ & \\
\hline Multiparous & & & 0.404 \\
\hline $\begin{array}{l}\text { Almost } 90 \%-100 \% \text { of } \\
\text { the time }\end{array}$ & $3(2.19)$ & $15(1.97)$ & \\
\hline $60 \%-90 \%$ of the time & $11(8.03)$ & $57(7.47)$ & \\
\hline $30 \%-60 \%$ of the time & $25(18.25)$ & $111(14.55)$ & \\
\hline$<30 \%$ of the time & $98(71.53)$ & $580(76.02)$ & \\
\hline Type of episiotomy used & & & 0.506 \\
\hline Midline & $1(0.73)$ & $20(2.62)$ & \\
\hline $\begin{array}{l}\text { Mediolateral (7-8 } \\
\text { o'clock) }\end{array}$ & $12(8.76)$ & $54(7.08)$ & \\
\hline $\begin{array}{l}\text { Mediolateral (4-5 } \\
\text { o'clock) }\end{array}$ & $124(90.51)$ & 689 (90.30) & \\
\hline \multicolumn{4}{|l|}{$\begin{array}{l}\text { Reasons for performing } \\
\text { episiotomy* }\end{array}$} \\
\hline $\begin{array}{l}\text { Reduce third-degree or } \\
\text { fourth-degree perineal } \\
\text { laceration }\end{array}$ & 115 (83.94) & 608 (79.69) & 0.249 \\
\hline Operative birth & $18(13.14)$ & $122(15.99)$ & 0.397 \\
\hline $\begin{array}{l}\text { Thick/swollen } \\
\text { perineum }\end{array}$ & $64(46.72)$ & $433(56.75)$ & 0.030 \\
\hline Easy to suture & $14(10.22)$ & $90(11.80)$ & 0.596 \\
\hline $\begin{array}{l}\text { Shorten the second } \\
\text { stage of labour }\end{array}$ & $51(37.23)$ & $260(34.08)$ & 0.476 \\
\hline Afraid of fetal distress & $70(51.09)$ & $481(63.04)$ & 0.008 \\
\hline Other & $29(21.17)$ & $158(20.71)$ & 0.903 \\
\hline
\end{tabular}

*More than one response possible.

episiotomy in nulliparas over $60 \%$ of the time. Among multiparous women, $76.02 \%$ of midwives and $71.53 \%$ of obstetricians performed episiotomy less than $30 \%$ of the time. The first reason for performing episiotomy identified by obstetricians $(83.94 \%)$ and midwives $(79.69 \%)$ was to reduce third-degree or fourth-degree perineal laceration. The second reason for performing episiotomy reported by obstetricians $(51.09 \%)$ was fear of fetal distress. Midwives were more likely than obstetricians to report thick/swollen perineum $(56.75 \%, \mathrm{p}<0.05)$ and fear of fetal distress $(63.04 \%, \mathrm{p}<0.01)$ as reasons for performing episiotomies. Due to unskilled techniques and perceived anxiety of its safety, operative vaginal delivery (forceps and vacuum) is rarely performed by obstetricians and midwives in China. 


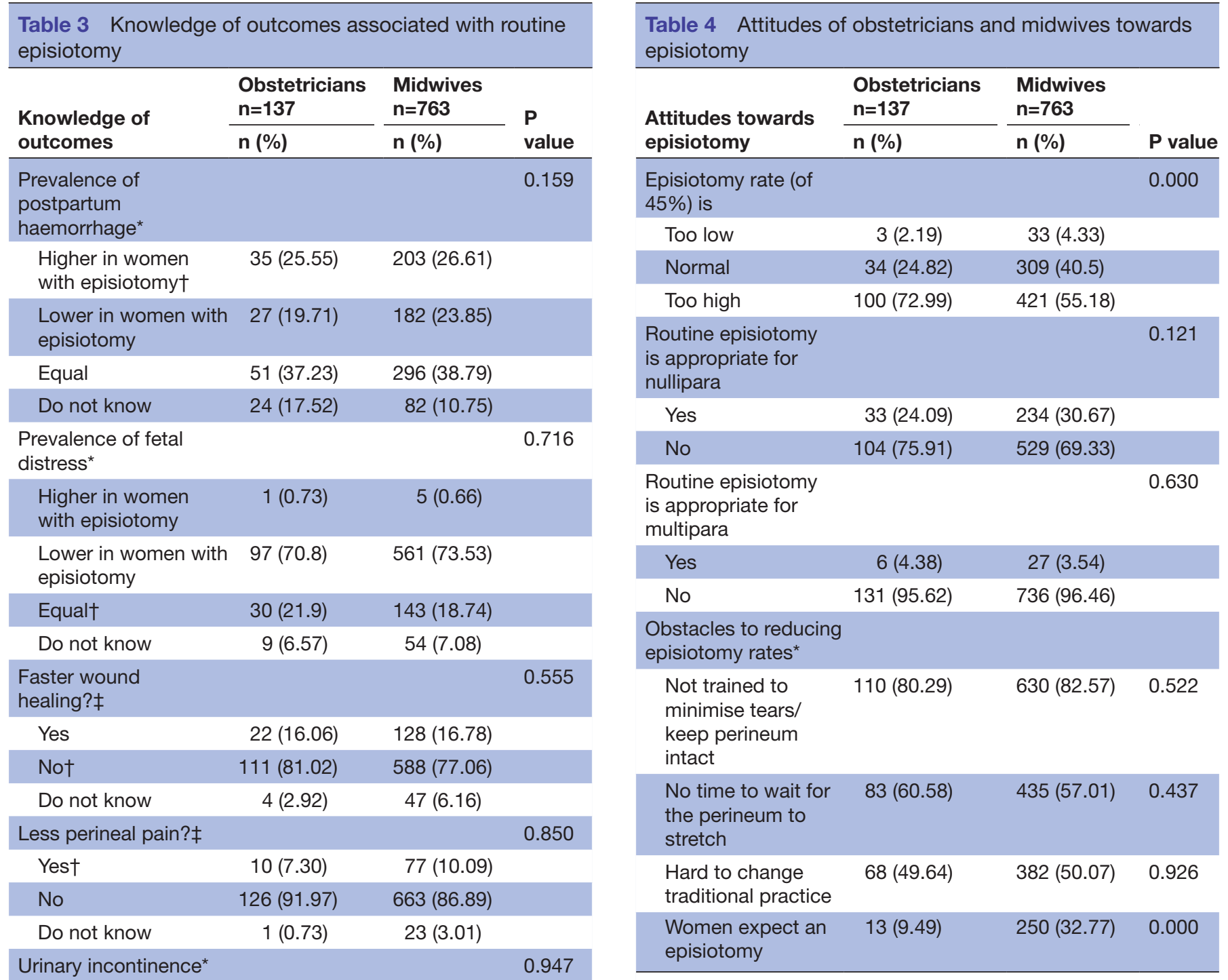

\begin{tabular}{|c|c|c|c|}
\hline Yes & $17(12.41)$ & $102(13.37)$ & \\
\hline Not & $106(77.37)$ & $578(75.75)$ & \\
\hline Do not know & $14(10.22)$ & $83(10.88)$ & \\
\hline Pelvic organ prolapsed* & & & 0.091 \\
\hline Yes & $33(24.09)$ & $114(14.94)$ & \\
\hline Not & $91(66.42)$ & $580(76.02)$ & \\
\hline Do not know & $13(9.49)$ & $69(9.04)$ & \\
\hline
\end{tabular}

${ }^{*}$ Compared with women without episiotomy.

†Correct answers.

¥Compared with women with second-degree laceration.

\section{Knowledge regarding outcomes of routine episiotomy}

The study revealed an average knowledge level regarding episiotomy among participants. The overall score ranged from 0 to 6 , with a mean of 4.15 . The difference between obstetricians (4.13, $\mathrm{SD}=0.97)$ and midwives (4.16, $\mathrm{SD}=1.12$ ) was not significant. Similarly, obstetricians and midwives did not differ in their responses to several individualised questions (table 3 ). The proportion of correct answers ranged from $26 \%$ (episiotomy increased the risk

*More than one response possible.

of postpartum haemorrhage; obstetricians) to $92 \%$ (episiotomy did not reduce perineal pain; obstetricians).

\section{Attitudes of participants towards episiotomy}

We showed the attitudes of obstetricians and midwives towards episiotomy in table 4 . Obstetricians $(72.99 \%)$ were more likely than midwives $(55.18 \%)$ to recognise that the current $45 \%$ rate of episiotomy in China was too high $(\mathrm{p}<0.001)$. Majority of the obstetricians $(75.91 \%)$ and midwives $(69.33 \%)$ agreed that routine episiotomy was not appropriate for nulliparas. Almost all obstetricians $(95.62 \%)$ and midwives $(96.46 \%)$ recognised that routine episiotomy was not appropriate for multiparas. All participants identified obstacles to reducing the rate of episiotomy. The most common obstacle for obstetricians $(80.29 \%)$ and midwives $(82.57 \%)$ was lack of training to minimise tears. The second frequent obstacle identified by obstetricians $(60.58 \%)$ and midwives $(57.01 \%)$ was that there was not enough time to wait for the perineum to stretch. About half of obstetricians (49.64\%) and midwives $(50.07 \%)$ considered it difficult to change 
Table 5 Contingency table analysis of nulliparous and multiparous episiotomy rate

\begin{tabular}{|c|c|c|c|c|c|}
\hline & $\begin{array}{l}\text { Almost } 90 \%-100 \% \\
\text { of the time }\end{array}$ & $60 \%-90 \%$ of the time & $30 \%-60 \%$ of the time & $<30 \%$ of the time & \\
\hline & $\begin{array}{l}\text { Nulliparous/ } \\
\text { multiparous } \\
\mathrm{n}(\%)\end{array}$ & $\begin{array}{l}\text { Nulliparous/ } \\
\text { multiparous } \\
\mathrm{n}(\%)\end{array}$ & $\begin{array}{l}\text { Nulliparous/ } \\
\text { multiparous } \\
\mathrm{n}(\%)\end{array}$ & $\begin{array}{l}\text { Nulliparous/ } \\
\text { multiparous } \\
\mathrm{n}(\%)\end{array}$ & $\begin{array}{l}\text { Total } \\
(\mathrm{N}=900)\end{array}$ \\
\hline \multicolumn{6}{|c|}{$\begin{array}{l}\text { Experience } \\
\text { (years) }\end{array}$} \\
\hline$<5$ & $23(13.07) / 7(3.98)$ & $44(25.00) / 16(9.09)$ & $47(26.70) / 24(13.64)$ & $62(35.23) / 129$ (73.30) & $176(19.56)$ \\
\hline $5-10$ & $21(7.87) / 2(0.75)$ & $65(24.34) / 22(8.24)$ & $88(32.96) / 48$ (17.98) & $93(34.83) / 195$ (73.03) & $267(29.67)$ \\
\hline $11-20$ & $14(5.47) / 5(1.95)$ & $41(16.02) / 20(7.81)$ & $92(35.94) / 31$ (12.11) & $109(42.58) / 200(78.13)$ & $256(28.44)$ \\
\hline$>20$ & $13(6.47) / 4(1.99)$ & $29(14.43) / 10(4.98)$ & $93(46.27) / 33$ (16.42) & $66(32.84) / 154(76.62)$ & $201(22.33)$ \\
\hline \multicolumn{6}{|c|}{ Hospital level } \\
\hline Level 1 & $3(8.11) / 0(0.00)$ & $7(18.92) / 4(10.81)$ & $4(10.81) / 4(10.81)$ & $23(62.16) / 29$ (78.38) & $37(4.11)$ \\
\hline Level 2 & $46(11.41) / 13(3.23)$ & $92(22.83) / 34(8.44)$ & $163(40.45) / 68$ (16.87) & $102(25.31) / 288(71.46)$ & $403(44.78)$ \\
\hline Level 3 & $22(4.78) / 5(1.09)$ & 80 (17.39)/30 (6.52) & 153 (33.26)/64 (13.91) & $205(44.57) / 361(78.48)$ & $460(51.11)$ \\
\hline
\end{tabular}

traditional behaviours. Midwives $(32.77 \%)$ were more likely than obstetricians $(9.49 \%)$ to deem that women expected an episiotomy $(\mathrm{p}<0.001)$.

\section{Effect of hospital level and work experience on episiotomy items}

In addition, we classified the frequency of performing episiotomy among nulliparas and multiparas according to work experience and hospital level in table 5. The difference between obstetricians and midwives $(\mathrm{p}=0.238)$ was not significant. Of the participants in tertiary hospitals, $45 \%$ reported performing episiotomy in nulliparas less than $30 \%$ of the time, compared with $25 \%$ of the participants in secondary hospitals $(p<0.05)$. At the same time, participants $(40 \%)$ in secondary hospitals contributed the most number of episiotomy procedures between $30 \%$ and $60 \%$ of the time among nulliparas. Similarly, secondary hospitals expressed a higher frequency of performing episiotomy among multiparas than tertiary hospitals.

The largest participants $(\mathrm{n}=699)$ who worked for less than 20 years reported performing episiotomy among nulliparas less than $30 \%$ of the time, compared with $30 \%-60 \%$ of the time among senior clinicians $(46.27 \%)$ who have worked for more than 20 years.

Table 6 shows the ANOVA of the effects of hospital level and work experience on episiotomy. The overall impact of hospital level was more significant than work experience. The effect of hospital level was significant in the items 'episiotomy performance for nullipara' ( $\mathrm{p}=0.006 / 0.000$ ) and the reasons identified as 'reduce $3 \mathrm{rd}$ and 4 th degree perineal laceration' $(\mathrm{p}=0.037,0.007<0.05)$ and 'easy to suture' ( $\mathrm{p}=0.002 / 0.028)$. In addition, the experience $\times$ hospital level interaction among obstetricians was significant in 'episiotomy performance for nullipara' $(\mathrm{p}=0.017)$ and 'less perineal pain' $(\mathrm{p}=0.024)$.

\section{DISCUSSION}

\section{A gap in rates of episiotomy still exists between Asia and Europe}

We investigated the knowledge, attitude and experience of episiotomy among a representative sample of midwives and obstetricians in Chinese public hospitals for the first time, aiming to collect information and remedy the current situation. Nine hundred participants completed the questionnaire. An average level of knowledge on complications and overuse was identified among participants. Episiotomy was performed more frequently in secondary hospitals than in tertiary hospitals. Senior clinicians were more likely to perform episiotomy than younger ones. Almost half of the clinicians considered the current rate of episiotomy to be right or too low. The most common reason for performing episiotomy identified by obstetricians and midwives was reducing third-degree or fourth-degree perineal laceration. Both obstetricians and midwives agreed that the most significant obstacle to reducing the rate of episiotomy was lack of training on reducing perineal tears.

The rates of episiotomy are still very high in Asian nations, such as $86 \%$ in Vietnam, ${ }^{27} 60 \%$ in India $^{14}$ and $94.5 \%$ in Cambodia. ${ }^{12}$ China had been considered to have a high rate of episiotomy for a long time. When referring to high rates of episiotomy, China is often cited as an example, with an episiotomy rate of around $80 \% .{ }^{13} 3136$ After restrictive episiotomy was urged by the Chinese Medical Association in $2016^{9}$ and the China Maternal and Child Health Association in $2019,{ }^{37}$ the rate of episiotomy had significantly decreased to $45 \%$ in China. The knowledge level on episiotomy complications among participants was higher than Vietnam and Jordan as well. ${ }^{27}{ }^{34}$ However, a gap in rates of episiotomy still exists between China and Europe,${ }^{1011}$ which is our target and impetus for improvement. It is generally believed that Asian women had shorter perineum length than Caucasians, putting them 
Table 6 ANOVA of the effects of hospital level and work experience on episiotomy

\begin{tabular}{|c|c|c|c|c|c|c|}
\hline $\begin{array}{l}\text { Use, knowledge and } \\
\text { attitude towards } \\
\text { episiotomy }\end{array}$ & \multicolumn{2}{|l|}{ Experience } & \multicolumn{2}{|l|}{ Hospital level } & \multicolumn{2}{|c|}{ Experiencexhospital level } \\
\hline Nulliparous & $1.58(0.198)$ & $3.14(0.025)$ & $5.43(0.006)$ & $19.07(0.000)$ & $2.87(0.017)$ & $1.18(0.317)$ \\
\hline Multiparous & $1.76(0.158)$ & $0.89(0.444)$ & $2.39(0.096)$ & $5.33(0.005)$ & $0.86(0.511)$ & $0.60(0.731)$ \\
\hline Type of episiotomy used & $0.74(0.530)$ & $0.29(0.832)$ & $1.16(0.317)$ & $0.20(0.822)$ & $0.51(0.769)$ & $0.31(0.934)$ \\
\hline \multicolumn{7}{|c|}{ Reasons for performing episiotomy } \\
\hline Operative birth & $1.20(0.312)$ & $4.01(0.008)$ & $0.06(0.943)$ & $1.07(0.345)$ & $0.32(0.898)$ & $0.98(0.439)$ \\
\hline $\begin{array}{l}\text { Thick/swollen } \\
\text { perineum }\end{array}$ & $3.49(0.018)$ & $0.43(0.731)$ & $0.15(0.863)$ & $0.22(0.800)$ & $0.68(0.639)$ & $0.49(0.816)$ \\
\hline Afraid of fetal distress & $1.34(0.266)$ & $1.29(0.278)$ & $2.55(0.082)$ & $3.28(0.038)$ & $0.20(0.962)$ & $0.68(0.663)$ \\
\hline Other & $1.00(0.396)$ & $1.31(0.268)$ & $0.31(0.734)$ & $1.16(0.314)$ & $0.36(0.878)$ & $0.82(0.555)$ \\
\hline $\begin{array}{l}\text { Prevalence of } \\
\text { postpartum } \\
\text { haemorrhage }\end{array}$ & $2.30(0.080)$ & $1.36(0.254)$ & $0.72(0.487)$ & $1.24(0.291)$ & $0.70(0.625)$ & $0.99(0.430)$ \\
\hline $\begin{array}{l}\text { Prevalence of fetal } \\
\text { distress }\end{array}$ & $0.32(0.813)$ & $1.39(0.245)$ & $7.11(0.001)$ & $1.56(0.211)$ & $1.23(0.300)$ & $0.62(0.711)$ \\
\hline Faster wound healing? & $3.03(0.032)$ & $0.57(0.635)$ & $4.04(0.020)$ & $2.68(0.069)$ & $1.35(0.246)$ & $0.91(0.489)$ \\
\hline Less perineal pain? & $0.79(0.500)$ & $1.13(0.035)$ & $5.21(0.007)$ & $0.40(0.700)$ & $2.70(0.024)$ & $1.06(0.386)$ \\
\hline $\begin{array}{l}\text { Routine episiotomy is } \\
\text { appropriate for multipara }\end{array}$ & $0.33(0.804)$ & $0.35(0.789)$ & $0.29(0.746)$ & $0.69(0.501)$ & $1.14(0.345)$ & $0.46(0.837)$ \\
\hline \multicolumn{7}{|l|}{$\begin{array}{l}\text { Obstacles to reducing } \\
\text { episiotomy rates* }\end{array}$} \\
\hline $\begin{array}{l}\text { Not trained to } \\
\text { minimise tears/keep } \\
\text { perineum intact }\end{array}$ & $0.93(0.428)$ & $1.77(0.152)$ & $0.02(0.978)$ & $0.82(0.439)$ & $1.81(0.115)$ & $1.15(0.332)$ \\
\hline $\begin{array}{l}\text { No time to wait for the } \\
\text { perineum to stretch }\end{array}$ & $0.19(0.901)$ & $1.41(0.239)$ & $0.47(0.627)$ & $0.61(0.546)$ & $0.41(0.842)$ & $1.12(0.351)$ \\
\hline $\begin{array}{l}\text { Hard to change } \\
\text { traditional practice }\end{array}$ & $1.91(0.132)$ & $0.88(0.450)$ & $0.86(0.426)$ & $1.84(0.160)$ & $0.56(0.733)$ & $1.49(0.179)$ \\
\hline $\begin{array}{l}\text { Women expect an } \\
\text { episiotomy }\end{array}$ & $0.44(0.727)$ & $0.18(0.907)$ & $0.44(0.645)$ & $1.49(0.225)$ & $0.97(0.440)$ & $0.46(0.839)$ \\
\hline
\end{tabular}

$P$ values are in parentheses.

The bold values indicate that it is significant $(P$ values $<0.05)$

*More than one response possible.

ANOVA, analysis of variance.

at a higher risk of perineal injury. ${ }^{38}$ However, it is proven that the increased risk only applied to Asian-born women who deliver in Western countries and that Asian women in an Asian setting had a lower risk. ${ }^{39}$ A prospective study among Chinese women reported a similar mean perineal length to that reported for other populations, and 
restrictive episiotomy was generalised to Chinese women without compromising perineal safety. ${ }^{32}$ Considering the lack of training and the different culture in China, it may be unrealistic to expect a decrease in the rate of episiotomy to $10 \%$ in the short term, as recommended by WHO. ${ }^{6}$ However, efforts have been made to protect the perineum instead of performing routine episiotomy within hospitals in China. A slow birth and stretched perineum are fundamental to preventing third-degree or fourth-degree tears. Hands-off techniques, perineal massage and warm compress are widely used by midwives in China, helping reduce the number of episiotomies, according to a Cochrane review. ${ }^{40}$ Freedom position labour and birth and immersion in water during the first and second stage of labour appear to have contributed to perineum stretching in Chinese hospitals. A Cochrane review showed similar results, where fewer episiotomies were performed when birth is delivered in upright, stool or squatting position compared with supine position. ${ }^{41}{ }^{42}$ A randomised controlled trial (RCT) in Spain ${ }^{43}$ also showed that the alternative birth model significantly reduced the number of episiotomy compared with the traditional birth model.

\section{Complicated reasons for performing routine episiotomy}

Medical practices are largely socially determined. In addition to physiological reasons, a deeper problem is the backward operation system of medical malpractice. In case of severe perineal tears caused by the absence of an episiotomy, the hospital may assume all the responsibilities in a lawsuit. Therefore, to avoid unexpected situations in China, public hospitals have a tacit understanding to implement episiotomy for vaginal birth. Third-degree or fourth-degree laceration is one of the sensitive quality evaluation indexes of obstetric care across China. ${ }^{44}$ Midwives with third-degree or fourth-degree tears medical records will be incorporated into the files, which may hinder future promotion. As shown in table 2, compared with spontaneous vaginal laceration, almost all obstetricians and midwives believed that episiotomy could reduce the risk of third-degree and fourth-degree perineal laceration, which was the best reason for using this approach. However, evidence suggested that, rather than providing a preventive effect, episiotomy results in severe perineal lacerations. ${ }^{45}$ Selective episiotomy may result in $30 \%$ fewer women experiencing third-degree or fourth-degree tears than routine episiotomy (8 RCTs, 5375 women). ${ }^{2}$ Midline episiotomy even was a powerful risk factor for thirddegree and fourth-degree perineal lacerations. Moreover, routine episiotomy reduces early risk of perineal laceration but increases future risk. Women who had an episiotomy had a doubled risk of second-degree laceration in subsequent vaginal delivery compared with those without an episiotomy, which may be due to the decrease in pelvic floor muscle strength caused by the previous episiotomy. ${ }^{12}$ It is imperative to reduce the rate of episiotomy among nulliparas in the context of the two-child policy. A considerable number of obstetricians and midwives chose episiotomies to prevent neonatal distress. When the fetus is at risk during childbirth, any procedure seems to be allowed, even if it is potentially harmful to the mother. We found a similar result in another episiotomy survey ${ }^{46}: 95 \%$ of patients were able to accept episiotomy performed to prevent neonatal distress, compared with $82 \%$ to prevent third or fourth tears, suggesting that women were more likely to protect their children than themselves. However, as decreases in fetal heart rate are more detected rather than real neonatal distress, we are concerned about the overuse of episiotomy by midwives claiming to involve fetal distresss and more use episiotomy.

\section{Obstacles to reducing the rate of episiotomy}

The rate of restrictive episiotomy recommended by the WHO does not exceed $10 \% .{ }^{6}$ However, $42.11 \%$ of participants still thought that the current episiotomy rate (45\%) was about right or too low, far from the current evidencebased medicine. Obstetricians and midwives believed that lack of training on perineal tear prevention was the most common obstacle to reducing the rate of episiotomy, which indicated that clinicians needed continuing education. In 2015, a standardised training base for midwives was established to conduct standardised and systematic training of midwives in China, but seats for each batch were limited. Therefore, we recommend that, under experienced supervision, compulsory education and training programmes be formally implemented as early as possible in obstetric clinical training. Besides, we also need other methods to help clinicians keep the habit of restrictive episiotomy. Zhang-Rutledge $e t a t^{77}$ concluded that education, operative feedback and the Hawthorne effect were associated with a decrease in rates of episiotomy (from $7.2 \%$ to less than 5\%). As far as our hospital is concerned, episiotomy was routinely performed before 2016 and the rate of episiotomy has significantly decreased to $25 \%-35 \%$ recently after adopting a publicity policy of personal episiotomy rate. Meanwhile, regular reviews could remind participants to maintain behavioural changes during weekly staff meetings. The second common obstacle reported by obstetricians and midwives was the lack of time to wait for the perineum to stretch. It is partly due to an emergency requiring saving neonatal lives, such as those with neonatal distress and cord prolapse, or an emergency requiring shortening the second stage of labour, such as maternal heart disease or eclampsia, or thick or swollen perineal body tissue. Furthermore, it seems that overwhelmed delivery rooms and shortage of time lead to overmedicalised delivery, suggesting an expansion in the scale of birthing facilities and healthcare providers during birth. Prior studies showed that lack of time was a reason for cutting the perineum in order to hasten delivery by birth attendants, given the high number of women in the labour ward. ${ }^{28}$ Instrument-assisted stretching using an inflatable silicon ball with a pressure display hand pump gradually stretches the vagina and the perineum in late pregnancy. The stretching is performed via widening the hiatus in 
the axial plane, similar to what happens during perineal massage. de Freitas et al conducted a pilot study to explore the effects of perineal preparation techniques on tissue extensibility and muscle strength. ${ }^{48}$ They concluded that the techniques increased extensibility without altering the strength of the pelvic floor muscle, which may provide us with a new idea to facilitate perineum stretching. A third of midwives reported that women were expecting an episiotomy. In fact, because delivery is complicated and urgent, midwives often lead the decision-making process of episiotomy. Out of concern for maternal and neonatal health, a woman said she would not reject the midwives' advice. In general, women had little knowledge about episiotomy and were not well informed; some did not even know what had been done until after the episiotomy. ${ }^{49}$ Instead of expectation, the effect of episiotomy was described in Chinese as a 'psychological shadow' of postpartum sexual life and the next childbirth, which are societal norms that meant women are expected to suffer alone and not complain. ${ }^{50}$

As shown in tables 5 and 6 , the episiotomy practice at different hospital levels showed difference. Compared with secondary hospitals, the rate of episiotomy in tertiary hospitals was lower, and the knowledge level of obstetricians and midwives was higher, probably as a result of staff qualification being higher and standardised training being disseminated with the latest evidence-based medicine in tertiary hospitals. However, the maternity and child health hospitals are secondary hospitals in most regions of China, which need standardised midwifery training. Senior midwives were more likely to use episiotomy than the young, probably attributed to senior midwives treating more high-risk cases, while there was a small difference between senior and young midwives in terms of using caesarean section, induction and operative vaginal delivery, which implies these differences were not driven by patient risk factors. ${ }^{51}$ The literature indicated that the age gap of every 10 years among obstetricians caused a $6 \%$ increase in episiotomy rate. We have reason to believe that older obstetricians are less likely to persist and be aware of evidence-based medicine. Klein et $a \tilde{l}^{2}$ found that obstetricians with a higher episiotomy rate had a higher caesarean delivery rate, which was associated with personal overmedical style. If practice is constrained by the persistence of beliefs, it is difficult for obstetricians to abandon outdated operations as well as implement new midwifery technologies. Many medical specialty societies have started requiring physicians to recertify every 10 years. Since 2011, societies have paid bonuses to physicians who pass 'maintenance of certification' examinations, which provide older physicians with an opportunity to identify mismatches between practice patterns and current evidence.

\section{Limitations}

Our study has several limitations. First, we only investigated the knowledge, attitude and experience towards episiotomy. Perineal suturing was not studied since knowledge on perineal suturing involves numerous areas of evaluation, materials selection, operation points and so on. Second, the paper is a cross-sectional study rather than a prospective cohort study, which restricts the ability to infer a causal relationship between attitudes and episiotomy practice. Third, the questionnaire is anonymous, without knowledge of the names of the participants who come from 90 hospitals of diverse cities, and other medical records were not available due to patient privacy, which hinders finding individual medical record reviews and exploring the effects of knowledge, attitude and experience of delivery service.

\section{CONCLUSION}

This study identifies that obstetricians and midwives in China have certain beliefs about the reasons and outcomes of performing episiotomy that contradict current research evidence. We also identify that episiotomy practice among Chinese obstetricians and midwives presents a difference with hospital levels for the first time. This study is one step in a planned programme of work attempting to facilitate practice changes in China. Continuing education, evidence-based clinical policies and guidelines are imperative. This non-experimental design limits the continued discussion of the causal relationship between attitude and episiotomy practice, which requires more indepth research.

Acknowledgements The authors would like to thank the editor and three anonymous referees for their constructive comments, which have significantly improved the paper. The authors also thank the valuable contribution of the obstetricians and midwives who participated in this study, and Peng Guo, Wang Zhang, Lingli Han and Yumei Xu for their help.

Contributors JY completed the manuscript writing and data analysis. HB served as a consultant to JY and directed her to complete the experimental design.

Funding This research is supported by the joint construction project of Henan Province medical science and technology research plan (no. SBGJ2018049).

Competing interests None declared.

Patient and public involvement Patients and/or the public were not involved in the design, or conduct, or reporting, or dissemination plans of this research.

Patient consent for publication Not required.

Ethics approval The study was supported by the Ethics Committee of the Third Affiliated Hospital of Zhengzhou University and the Chinese Health Department.

Provenance and peer review Not commissioned; externally peer reviewed.

Data availability statement Data are available upon reasonable request.

Open access This is an open access article distributed in accordance with the Creative Commons Attribution Non Commercial (CC BY-NC 4.0) license, which permits others to distribute, remix, adapt, build upon this work non-commercially, and license their derivative works on different terms, provided the original work is properly cited, appropriate credit is given, any changes made indicated, and the use is non-commercial. See: http://creativecommons.org/licenses/by-nc/4.0/.

ORCID iD

Hua Bai http://orcid.org/0000-0003-4944-7156

\section{REFERENCES}

1 Béchard F, Geronimi J, Vieille P, et al. Are we performing episiotomies correctly? A study to evaluate French technique in a high-risk maternity unit. J Gynecol Obstet Hum Reprod 2018;47:331-8. 
2 Jiang H, Qian X, Carroli G, et al. Selective versus routine use of episiotomy for vaginal birth. Cochrane Database Syst Rev 2017;2:112-20.

3 Quoc Huy NV, Phuc An LS, Phuong LS, et al. Pelvic floor and sexual dysfunction after vaginal birth with episiotomy in vietnamese women. Sex Med 2019;7:514-21.

4 Carroli G, Mignini L. Episiotomy for vaginal birth. Cochrane Database Syst Rev 2009;21:CD000081.

5 Main EK. New perinatal quality measures from the National quality forum, the joint commission and the leapfrog group. Curr Opin Obstet Gynecol 2009;21:532-40.

6 World Health Organization Division of Family Health Maternal Health and Safe Motherhood. Care in normal birth: a practical guide. Report of a technical working group. Geneva: World Health Organization, 1996

7 Sagi-Dain L, Sagi S. Indications for episiotomy performance - a cross-sectional survey and review of the literature. J Obstet Gynaecol 2016;36:361-5.

8 CNGOF. Recommandations Pour La PratiqueMedicale. L'e'pisiotomie 2005.

9 Obstetrics Group, Obstetrics and Gynecology Society, Chinese Medical Association. Clinical guidelines for operative vaginal delivery. Chin J Obstet Gynecol 2016:51:565-7.

10 Clesse C, Lighezzolo-Alnot J, De Lavergne S, et al. Statistical trends of episiotomy around the world: comparative systematic review of changing practices. Health Care Women Int 2018;39:644-62.

11 Graham ID, Carroli G, Davies C, et al. Episiotomy rates around the world: an update. Birth 2005;32:219-23.

12 Sangkomkamhang U, Kongwattanakul K, Kietpeerakool C, et al. Restrictive versus routine episiotomy among Southeast Asian term pregnancies: a multicentre randomised controlled trial. BJOG 2020;127:397-403.

13 Zimmo K, Laine K, Fosse E, et al. Episiotomy practice in six Palestinian hospitals: a population-based cohort study among singleton vaginal births. BMJ Open 2018;8:e021629.

14 Singh S, Thakur T, Chandhiok N, et al. Pattern of episiotomy use \& its immediate complications among vaginal deliveries in 18 tertiary care hospitals in India. Indian J Med Res 2016;143:474-80.

15 Frass $\mathrm{KA}$, Al-Harazi $\mathrm{AH}$. Episiotomy is still performed routinely in Yemeni women. Saudi Med J 2010;31:764-7.

16 Schantz C, Sim KL, Ly EM, et al. Reasons for routine episiotomy: a mixed-methods study in a large maternity hospital in Phnom Penh, Cambodia. Reprod Health Matters 2015;23:68-77.

17 Blondel B, Alexander S, Bjarnadóttir RI, et al. Variations in rates of severe perineal tears and episiotomies in 20 European countries: a study based on routine national data in Euro-Peristat project. Acta Obstet Gynecol Scand 2016;95:746-54.

18 Gundabattula SR, Surampudi K. Risk factors for obstetric anal sphincter injuries (OASI) at a tertiary centre in South India. Int Urogynecol J 2018;29:391-6.

$19 \mathrm{Yu}$ J, Wang F. Analysis of the incidence and risk factors of anal sphincter injury after vaginal delivery in women in Huangshi maternal and child health center of Hubei Province. Chin J Clin Obstet Gynecol 2019;20:439-40.

20 Boujenah J, Tigaizin A, Fermaut M, et al. Is episiotomy worthwile to prevent obstetric anal sphincter injury during operative vaginal delivery in nulliparous women? Eur J Obstet Gynecol Reprod Bio 2019;232:60-4.

21 Wang Q, Zheng S-X, Ni Y-F, et al. The effect of labor epidural analgesia on maternal-fetal outcomes: a retrospective cohort study. Arch Gynecol Obstet 2018;298:89-96.

22 Tung CW, Cheon WC, Tong WMA, et al. Incidence and risk factors of obstetric anal sphincter injuries after various modes of vaginal deliveries in Chinese women. Chin Med J 2015;128:2420-5.

23 Zhao Y, Xiao M, Tang F, et al. The effect of water immersion delivery on the strength of pelvic floor muscle and pelvic floor disorders during postpartum period: an experimental study. Medicine 2017;96:e8124.

24 Zhu L, Li L, Lang J-he, et al. Prevalence and risk factors for peri- and postpartum urinary incontinence in primiparous women in China: a prospective longitudinal study. Int Urogynecol J 2012;23:563-72.

25 Liang L, Min L, Li N. Survey on episiotomy among puerperal women in vaginal delivery from 2011 to 2014 . Maternal Child Health Care China 2015;07:1087-9.

26 National economy continued to recover in may. Available: http:// www.stats.gov.cn/tjsj/zxfb/201908/t2019082216928_98. html

27 Trinh AT, Roberts CL, Ampt AJ. Knowledge, attitude and experience of episiotomy use among obstetricians and midwives in Viet Nam. BMC Pregnancy Childbirth 2015;15:101-7.
28 Zhang M, Wang M, Zhao X, et al. Risk factors for episiotomy during vaginal childbirth: a retrospective cohort study in Western China. $J$ Evid Based Med 2018;11:233-41.

29 Lin GUO, Yan D, Zheng Z. Establishment of predictive model of midwives' decision on episiotomy during childbirth. Chin J Nurs 2019;54:1469-74.

30 Yan W, Biru L, Xinfen X. Investigation on the current situation of labor analgesia in Chinese medical institutions. J Nurs Science 2020;35:16-19.

31 Nassar AH, Visser GHA, Ayres-de-Campos D. FIGO safe motherhood and newborn health Committee. FIGO statement: restrictive use rather than routine use of episiotomy. Int $J$ Gynaecol Obstet 2019;146:17-19.

32 Lai CY, Cheung HW, Hsi Lao TT, et al. Is the policy of restrictive episiotomy generalisable? A prospective observational study. J Matern Fetal Neonatal Med 2009;22:1116-21.

33 Gyhagen M, Bullarbo M, Nielsen TF, et al. Prevalence and risk factors for pelvic organ prolapse 20 years after childbirth: a national cohort study in singleton primiparae after vaginal or caesarean delivery. BJOG 2013;120:152-60.

34 Khresheh R, Barclay L. Knowledge, attitude and experience of episiotomy practice among obstetricians and midwives in Jordan. Women Birth 2020;33:e176-81.

35 Hamilton LC. Statistics with STATA updated for version 9M. Thomson, Brooks Cole, 2006.

36 Goueslard K, Cottenet J, Roussot A, et al. How did episiotomy rates change from 2007 to 2014? Population-based study in France. BMC Pregnancy Childbirth 2018;18:208-18.

37 Midwives Branch of Maternal and Child Health Care of China Association. Guideline of repairing techniques and material selection in episiotomy and perineal tears. Chinese Nurs Manag 2019;19:453-7.

38 Trinh AT, Nippita TA, Dien TN, et al. Perineal length among vietnamese women. Taiwan J Obstet Gynecol 2017;56:613-7.

39 Bates LJ, Melon J, Turner R, et al. Prospective comparison of obstetric anal sphincter injury incidence between an Asian and Western Hospital. Int Urogynecol J 2019;30:429-37.

40 Aasheim V, Nilsen ABV, Reinar LM, et al. Perineal techniques during the second stage of labour for reducing perineal trauma. Cochrane Database Syst Rev 2017;6:66-72.

41 Gupta Janesh K, Akanksha S, Hofmeyr GJ. Position in the second stage of labour for women without epidural an aesthesia. Cochrane Database Syst Rev 2017;5:2-6.

42 Deliktas A, Kukulu K. A meta-analysis of the effect on maternal health of upright positions during the second stage of labour, without routine epidural analgesia. J Adv Nurs 2018;74:263-78.

43 Walker C, Rodríguez T, Herranz A, et al. Alternative model of birth to reduce the risk of assisted vaginal delivery and perineal trauma. Int Urogynecol J 2012;23:1249-56.

44 Ying HE, Hong, WANG Lin LI, et al. Analysis of sensitive quality indicators of obstetrics and gynecology nursing. Hosp Admin J Chin PLA 2020;27:483-7.

45 Muraca GM, Liu S, Sabr Y, et al. Episiotomy use among vaginal deliveries and the association with anal sphincter injury: a population-based retrospective cohort study. CMAJ 2019;191:E1149-58.

46 Alexander JW, Karantanis E, Turner RM, et al. Patient attitude and acceptance towards episiotomy during pregnancy before and after information provision: a questionnaire. Int Urogynecol J 2020;31:521-8

47 Zhang-Rutledge K, Clark SL, Denning S, et al. An initiative to reduce the episiotomy rate: association of feedback and the hawthorne effect with leapfrog goals. Obstet Gynecol 2017;130:146-50.

48 de Freitas SS, Cabral AL, de Melo Costa Pinto R, et al. Effects of perineal preparation techniques on tissue extensibility and muscle strength: a pilot study. Int Urogynecol J 2019;30:951-7.

$49 \mathrm{He}$ S, Jiang H, Qian X. Qualitative study on experiences R elated to episiotomy of women from Shanghai communities. Med Society 2019;32:14-17.

50 He S, Jiang H, Qian X, et al. Women's experience of episiotomy: a qualitative study from China. BMJ Open 2020;10:e033354.

51 Howard DH, Hockenberry J. Physician age and the abandonment of episiotomy. Health Serv Res 2019;54:650-7.

52 Klein MC, Kaczorowski J, Robbins JM, et al. Physicians' beliefs and behaviour during a randomized controlled trial of episiotomy: consequences for women in their care. CMAJ 1995;153:769-79. 